\title{
Antibiotic and Anti-Inflammatory Therapies for Cystic Fibrosis
}

\author{
James F. Chmiel ${ }^{1}$, Michael W. Konstan ${ }^{1}$, and J. Stuart Elborn ${ }^{2}$ \\ ${ }^{1}$ Department of Pediatrics, Case Western Reserve University School of Medicine, Rainbow Babies \\ and Children's Hospital, Cleveland, Ohio 44106 \\ ${ }^{2}$ Medicine and Surgery, Queens University Belfast, Belfast City Hospital, Belfast BT9 7AB, \\ Northern Ireland, United Kingdom \\ Correspondence: michael.konstan@case.edu
}

\begin{abstract}
Cystic fibrosis (CF) lung disease is characterized by chronic bacterial infection and an unremitting inflammatory response, which are responsible for most of CF morbidity and mortality. The median expected survival has increased from $<6$ mo in 1940 to $>38 \mathrm{yr}$ now. This dramatic improvement, although not great enough, is due to the development of therapies directed at secondary disease pathologies, especially antibiotics. The importance of developing treatments directed against the vigorous inflammatory response was realized in the 1990s. New therapies directed toward the basic defect are now visible on the horizon. However, the impact of these drugs on downstream pathological consequences is unknown. It is likely that antibiotics and anti-inflammatory drugs will remain an important part of the maintenance regimen for $\mathrm{CF}$ in the foreseeable future. Current and future antibiotic and antiinflammatory therapies for CF are reviewed.
\end{abstract}

\begin{abstract}
$A^{\text {lthough cystic fibrosis (CF) impacts many }}$ Aorgan systems, lung disease accounts for most of the morbidity and mortality (Davis et al. 1996). Abnormal or insufficient cystic fibrosis transmembrane conductance regulator (CFTR) leads from the defective gene and protein to an abnormal surface environment to a vicious cycle of obstruction, chronic infection, and inflammation (Chmiel et al. 2002a). Relieving obstruction with mucolytics and airway clearance, controlling infection with antibiotics, and reducing inflammation with anti-inflammatory drugs have been the cornerstones of a comprehensive pulmonary treatment program in $\mathrm{CF}$.
\end{abstract}

\section{INFECTION AND INFLAMMATION IN THE CF AIRWAY}

CF airways are most susceptible to chronic infection with Staphylococcus aureus, Hemophilus influenzae, Pseudomonas aeruginosa, Burkholderia cepacia complex organisms, Stenotrophomonas maltophilia, and Achromobacter xylosoxidans. Most of these microbes form biofilms, thus serving as persistent inflammatory stimuli (Chmiel and Davis 2003). When local host defense mechanisms are challenged by intercurrent viral or bacterial infections, massive numbers of neutrophils are recruited into the airway. Although inflammation is meant to eradicate infection, this ultimately fails, and the exaggerated

Editors: John R. Riordan, Richard C. Boucher, and Paul M. Quinton

Additional Perspectives on Cystic Fibrosis available at www.perspectivesinmedicine.org

Copyright (C) 2013 Cold Spring Harbor Laboratory Press; all rights reserved; doi: 10.1101/cshperspect.a009779

Cite this article as Cold Spring Harb Perspect Med 2013;3:a009779 
J.F. Chmiel et al.

inflammatory response that ensues is responsible for much of the lung's pathology.

The CF inflammatory response begins early in life, becomes persistent, and is often excessive relative to the burden of infection. Bronchoalveolar lavage (BAL) fluid from CF patients, including infants and patients with mild disease, contains large concentrations of inflammatory mediators and cells, particularly neutrophils (Konstan et al. 1993, 1994; Birrer et al. 1994; Armstrong et al. 1995, 1997; Balough et al. 1995; Bonfield et al. 1995a; Khan et al. 1995; Kirchner et al. 1996). The presence of large concentrations of inflammatory mediators in the absence of detectable pathogens suggests either that the inflammatory response operates independently of infection or that there is failure to terminate the inflammatory response once the inciting stimulus has been removed (Khan et al. 1995). The inflammatory response could be triggered by a transient viral or bacterial infection that then cannot be stopped. In addition, BAL studies show that infected CF infants have more inflammation than do similarly infected non-CF infants (Noah et al. 1997; Muhlebach et al. 1999).

Neutrophils, present in massive quantities, release actin, DNA, proinflammatory cytokines and chemokines, oxidants, and proteases. B cells and $\mathrm{T}$ cells, particularly TH-17 cells, also contribute to CF lung disease (Dubin et al. 2007). The continued presence of bacteria triggers an unrelenting inflammatory response that drives the persistent generation of proinflammatory mediators including neutrophil chemoattractants IL- 8 and $\mathrm{LTB}_{4}$, which recruit more neutrophils into the airways, fueling the vicious cycle of inflammation that leads to lung destruction (Konstan and Berger 1997; Chmiel et al. 2002a). Because the neutrophil plays a central role in CF airway pathophysiology, any anti-inflammatory drug developed for CF must, either directly or indirectly, address the neutrophil and its products (Table 1).

Airway surface fluid from CF patients contains large concentrations of inflammatory mediators including TNF- $\alpha$, IL- $1 \beta$, IL-6, IL-8, IL-17, and GM-CSF (Bonfield et al. 1995a; McAllister et al. 2005). The synthesis of these mediators is promoted by a few transcription
Table 1. Neutrophil chemoattractants and products targeted by anti-inflammatory drugs
I. Neutrophil chemoattractants
A. IL-8
B. $\mathrm{LTB}_{4}$
C. Complement components: C5a, C5a-des-Arg
D. Bacterial products: $N$-formyl-Met-Leu-Phe
II. Neutrophil products
A. Proteases (elastase)
B. DNA
C. Oxidants $\left(\mathrm{H}_{2} \mathrm{O}_{2}\right.$ and $\left.\mathrm{O}_{2}^{-}\right)$
D. IL-8
E. $\mathrm{LTB}_{4}$

factors including AP-1, NF- $\mathrm{B}$, and MAPK. In addition to a heightened proinflammatory arm, there appears to be inappropriately decreased counter-regulatory pathways, particularly those involving IL-10 and nitric oxide (NO) (Bonfield et al. 1995b, 1999; Balfour-Lynn et al. 1996; Grasemann et al. 1997). When counter-regulatory controls are abnormal, an imbalance occurs, resulting in prolonged and excessive inflammatory mediator production. It is possible that a combination of these mechanisms fuels the destructive inflammatory cascade. It is unlikely that a single defect in one pathway accounts for the entirety of the exaggerated inflammatory response. Multiple pathways are probably upregulated (i.e., pathways that activate the inflammatory response) or down-regulated (i.e., pathways that terminate the inflammatory response) in response to the cell's attempt to correct the underlying physiological abnormality due to abnormal CFTR. The end result is that the delicate balance between the pro- and anti-inflammatory arms is disrupted, and pathways promoting the activation and perpetuation of the inflammatory response are favored. A schematic of the CF airway is seen in Figure 1.

\section{THERAPIES DIRECTED AT BACTERIAL INFECTION}

The range of microorganisms, particularly bacteria that have been identified in the CF airway, is much wider than previously appreciated 


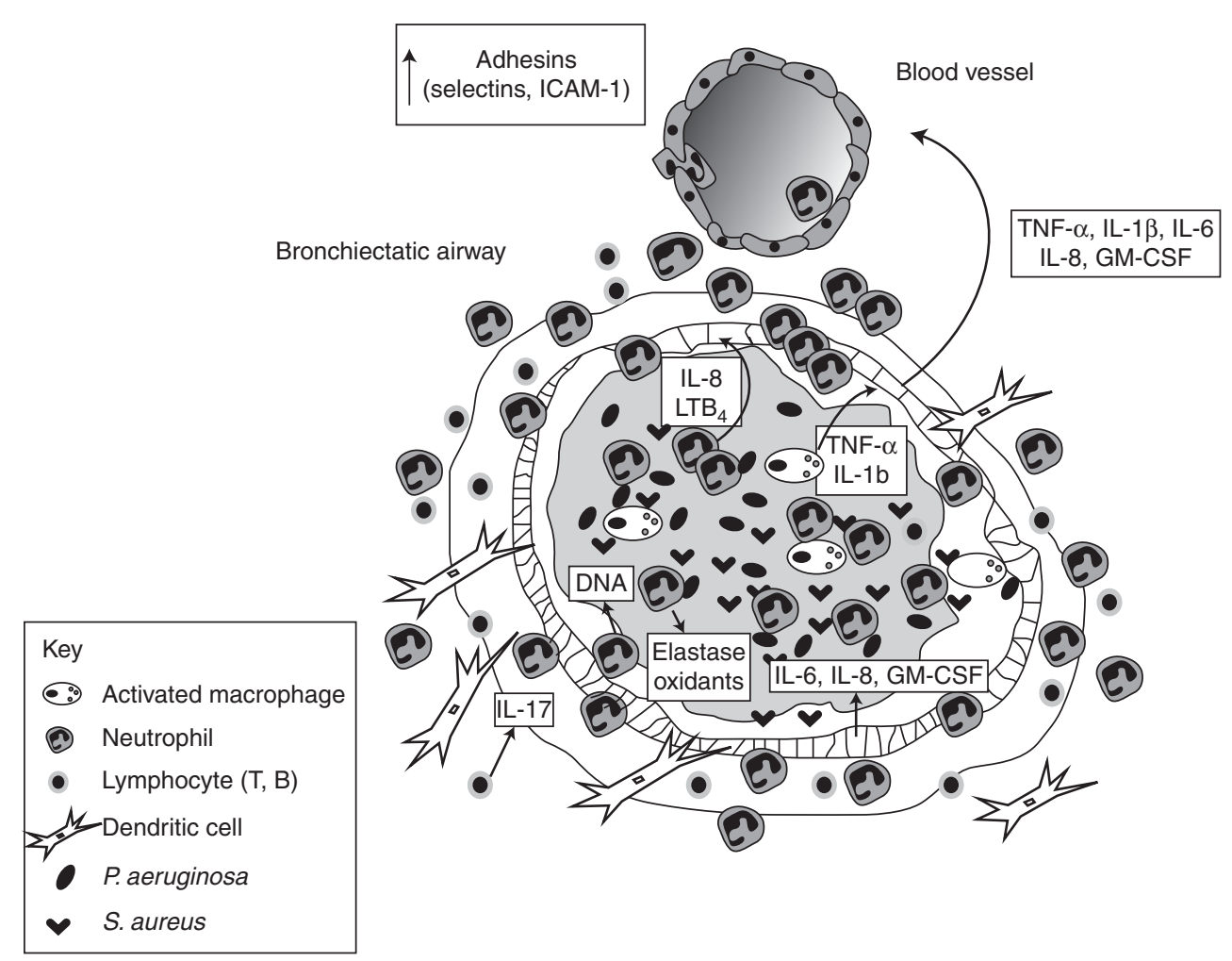

Figure 1. Infection and inflammation in the CF lung. CF lung disease is essentially an endobronchial/peribronchial process. The alveoli do not become involved until late in the disease course. In CF, the gene defect leads to an abnormal airway surface environment and then to airway obstruction with mucus (represented as an amorphous gray area in the center of the airway), chronic bacterial infection, and persistent inflammation. Although there are several different types of bacteria that infect the CF airway, S. aureus predominates early in life but typically yields to $P$. aeruginosa. However, most patients have polymicrobic infections, thus making selection of appropriate antibiotics for treatment of a pulmonary exacerbation difficult. The bacterial infection is associated with a vigorous inflammatory response that is characterized by a large neutrophilic infiltration. Other inflammatory cells are also involved in the inflammatory response including epithelial cells, macrophages, dendritic cells, B lymphocytes, and T lymphocytes. These cells release many inflammatory cytokines and mediators that further promote the inflammatory response. The inflammatory response is ineffectual in eliminating bacteria from the airway, but the excess inflammatory mediators released into the endobronchial and peribronchial spaces damage the airway wall architecture and ultimately lead to bronchiectasis. This figure focuses on the proinflammatory aspects of CF airway inflammation. The abnormalities in the counter-regulatory mechanisms in CF are not depicted.

(Tunney et al. 2008, 2011). Using molecular techniques, organisms that were previously unculturable, particularly microaerophilic and anaerobic bacteria, have been identified (Lipuma 2012). The virulence of these organisms and their complex interaction as an airway microbiome has yet to be fully established. However, there are some studies to suggest that the diversity or the lack of diversity in sputum and BAL from people with $\mathrm{CF}$ is associated with more severe and chronic disease, and this may in part be driven by antibiotic therapy (Tunney et al. 2011; Zhao et al. 2012)

Antimicrobial therapy in CF has a long history, and effective treatment of infection is thought to be one of the key advances that have resulted in improved outcomes over the past 50 years for people with CF (Döring et al. 2012). 
J.F. Chmiel et al.

S. aureus was identified in 1949 as the predominant pathogen in cultures taken from young children with CF. Subsequently, $P$. aeruginosa was identified as an organism associated with bronchiectasis and chronicity. From the late 1950s, $P$. aeruginosa was reported with increasing frequency from children with $\mathrm{CF}$, and the mucoid phenotype for $P$. aeruginosa was first described in 1966 (J Littlewood; www.cfmedicine.com). Specific antimicrobial therapy in $\mathrm{CF}$ has, therefore, been directed against these organisms. Over the subsequent decades, a range of other dominant organisms has presented challenges for antibiotic therapy. These include members of the B. cepacia complex, S. maltophilia, Achromobacter species, and other Gramnegative infections. Nontuberculous mycobacterial infection is also emerging as a new challenge for antibiotic treatment for people with CF.

\section{ANTIBIOTIC PROPHYLAXIS}

The presence of $S$. aureus in airway secretions from people with CF prompted early clinicians to consider the use of prophylactic antibiotics to prevent and control Staphylococcal infection in the early years (Smyth and Walters 2012). This type of treatment has been and, in some countries, remains controversial. In some small studies, prophylactic treatment from diagnosis with flucloxacillin has been associated with a reduction in the frequency of positive Staphylococcal airway sample cultures and a reduction in admission to hospital, but no long-term improvements have been shown in lung function. These observations were followed up with a clinical trial of cephalexin, a more broad-spectrum antibiotic, which did not show any efficacy. But in patients treated with long-term prophylaxis, there was an increase in the frequency of new infections with $P$. aeruginosa.

These observations have been supported by several registry studies. In a recent updated Cochrane Review, a meta-analysis of four studies including 401 patients under the age of seven was reported (Smyth and Walters 2012). In this analysis, no significant increase in the number of isolates of $P$. aeruginosa was shown between treated and untreated groups from reported studies, although there was a trend toward a lower cumulative isolation rate of $P$. aeruginosa in the patients treated with long-term antibiotics at 2-3 yr and a higher isolation rate from 4 to $6 \mathrm{yr}$. These studies used a range of antibiotics including flucloxacillin, co-trimoxazole, cefadroxil, and cephalexin. It is unclear what the clinical benefits of simply reducing the frequency of culture of $S$. aureus might be.

\section{Antibiotic Therapy for $S$. aureus}

S. aureus is a very common infecting organism in people with CF. This is most commonly methicillin-sensitive $S$. aureus (MSSA), but methicillin-resistant S. aureus (MRSA) is becoming increasingly common in the sputum of people with CF. The increased incidence of MRSA infection in people with CF is particularly concerning because it is associated with a more rapid rate of decline in lung function and worse survival (Dasenbrook et al. 2008, 2010). When either MSSA or MRSA is identified in sputum, it makes sense to attempt eradication. For MSSA, cephalexin, flucloxacillin, co-trimoxazole, and, additionally, in adults, tetracyclines can be used to do this. MRSA similarly may be eradicated with a combination of drugs used by clinicians including vancomycin, linezolid, rifampin, rifampicin, fusidic acid, tetracycline, and cotrimoxazole-based regimes. Several studies are currently trying to determine the best regime to treat this organism. Similarly, antibiotic approaches can be used to treat exacerbations in individuals who are chronically infected with this organism.

\section{ANTIBIOTIC THERAPY FOR INFECTION WITH $P$. aeruginosa ERADICATION THERAPY}

In contrast to the debate around antibiotic prophylaxis for $S$. aureus, there is currently no debate for antibiotic prophylaxis against $P$. aeruginosa in people with CF (Döring et al. 2012). There is currently a clinical trial in Europe using avian immunoglobulin Y antibodies, which are gargled, to explore if this novel inter- 
vention of treating the oropharynx might prevent $P$. aeruginosa acquisition in the lower airways (EUDRACT-2011-000801-39).

There is, however, a compelling rationale for antibiotic eradication therapy for $P$. aeruginosa in CF. This approach was championed by the Copenhagen Centre, who in early studies of this intervention using a historical comparative cohort, showed that there was a strong indication that the combination of inhaled colistin and oral ciprofloxacin resulted in approximately an $80 \%$ success in $P$. aeruginosa eradication (Valerius et al. 1991). Subsequent studies, such as the ELITE and EPIC studies, have shown that inhaled tobramycin for $4 \mathrm{wk}$ is also an effective antibiotic eradication therapy (Ratjen et al. 2010; Treggiari et al. 2011). In two small studies, no difference was identified between these two regimes with a comparable eradication rate (Taccetti et al. 2012; Proesmans 2013).

Early intervention is now a recommended part of most guidelines for the treatment of new or repeated infection with $P$. aeruginosa (Döring et al. 2012). It is less clear what the best treatment for failure to eradicate using either the colistin/ciprofloxacin or inhaled tobramycin regimes should be. A recent recommendation from a consensus group was that after two attempts at eradication using inhaled and oral therapy, intravenous antipseudomonal antibiotics should be considered. A clinical trial (Torpedo; www.torpedo-cf.org.uk/index. html) comparing colistin/ciprofloxacin and intravenous antibiotics is currently under way in the United Kingdom.

\section{Treatment of Chronic $P$. aeruginosa Infection}

In $\sim 75 \%$ of people with CF, $P$. aeruginosa eventually cannot be eradicated and chronic infection ensues (Döring et al. 2012). When this occurs, the bacteria frequently have a mucoid phenotype and exist in a biofilm. This and other important adaptions reduce the effectiveness of innate host defense and make treatment with antibiotics less effective (Williams and Davies 2012). When chronic infection has developed, treatment with long-term aerosolized antibiotics is an important and effective intervention.
Tobramycin (TOBI, Bramitob) and aztreonam lysine (Cayston) are approved therapies by most regulators throughout the world. Both of these treatments have shown superiority over placebo for measurements of lung function, quality of life, and reduction in pulmonary exacerbations (Döring et al. 2012). Colistin is also used in chronic suppressive therapy in its nebulized form. Tobramycin and colistin have recently been developed into dry-powder inhaled antibiotics. Tobramycin inhalation powder (TobiPodhaler) is approved by the EMA and also is under review by the FDA, and colistin inhalation powder (Colobreathe) has been approved by the EMA for treatment (Konstan et al. 2011; Schuster et al. 2012). Both of these drugs have shown noninferiority for key clinical outcomes to tobramycin delivered by nebulizer, and have increased cough as a common side effect.

In general, inhaled antipseudomonal antibiotics decrease bacterial burden (measured in $\mathrm{CFU} / \mathrm{g}$ of sputum), improve lung function and quality of life, and reduce the frequency of pulmonary exacerbations (Döring et al. 2012). Colistin is given every day, whereas tobramycin is licensed for administration as an alternate-month therapy. Many patients describe increased symptoms and reduced $\mathrm{FEV}_{1}$ during the month off tobramycin. Therefore, many patients cycle between two different inhaled antibiotics. The optimal regime for aerosolized antibiotic therapy as long-term suppressive therapy has yet to be determined. It is unlikely that a randomized controlled trial will allow any further direct comparisons between regimes or answer the challenging question of whether continuous nebulized antibiotics using alternate regimes, for example, alternating tobramycin, aztreonam lysine, and colistin, would be superior to the current recommended monthoff month-on regimes.

Several other inhaled antibiotic therapies against $P$. aeruginosa are in development. Two formulations of levofloxacin, ciprofloxacin as a dry powder inhaler, and ciprofloxacin and amikacin as liposomal formulations are in various stages of development and may become available in the near future (Döring et al. 2012). 
J.F. Chmiel et al.

Treating Exacerbations in Patients with Chronic $P$. aeruginosa Infection

Pulmonary exacerbations (PEs) are significant events in people with CF. These events are associated with an increase in pulmonary symptoms, systemic symptoms including weight loss, sometimes new clinical signs, physiological changes in lung function, and often evidence of local and systemic inflammation. Frequency of pulmonary exacerbations is associated with a more rapid decline in $\mathrm{FEV}_{1}$ and reduced survival (Smyth and Elborn 2008; Döring et al. 2012). Prevention of pulmonary exacerbations is, therefore, a key intervention, and there is good evidence that long-term suppressive antibiotic therapy, concomitant human DNase (Pulmozyme), azithromycin, and inhaled hypertonic saline reduce the time to the next exacerbation in clinical trials, and, by extrapolation, probably reduce the frequency of these events in people with CF. Optimizing long-term treatment to reduce these events and the inflammatory injury impact they have on the lungs in people with CF is a critically important intervention (Stenbit and Flume 2011).

Optimizing the antibiotic therapy and duration of treatment is important in treating pulmonary exacerbations. There is some evidence that $\sim 25 \%$ of pulmonary exacerbations result in a failure to return to baseline lung function and/or rapid relapse (Sanders et al. 2010; Stenbit and Flume 2011; Parkins et al. 2012). Selection of antibiotics for treatment of such exacerbations is largely empirical. Using current techniques to determine in vitro antimicrobial susceptibility does not appear to improve the outcomes (Döring et al. 2012). This is a particular problem with $P$. aeruginosa because with repeated antibiotic therapy, these organisms develop resistance. However, response to antibiotics does not appear to relate directly to in vitro susceptibility as currently determined in microbiology laboratories. The choice of initial antibiotics to treat a pulmonary exacerbation is often based on antibiotic susceptibility testing and is affected by patient tolerability. If clinical response is suboptimal, changes in antibiotic regimen are often made based on clin- ical experience irrespective of susceptibility testing.

There is a good historical and current rationale for the use of a combination of an extended-action penicillin and an aminoglycoside. Conventionally, this therapy has been for $14 \mathrm{~d}$, although in a recent registry-based study, $10 \mathrm{~d}$ may be a sufficient period of time for the majority of patients (Van Devanter et al. 2010). However, this approach has not been subjected to a prospective study.

\section{ANTIBIOTIC TREATMENT FOR OTHER BACTERIAL PATHOGENS IN CF}

\section{S. maltophilia and Achromobacter Species}

S. maltophilia and Achromobacter species are commonly isolated in CF sputum, although their prevalences are variable. Single centers have reported up to $25 \%$ prevalence of either organism. The clinical significance of these organisms is hard to determine, although it is clear that individual patients with either of these bacteria as their predominant pathogen can have progressive deterioration in lung function and pulmonary exacerbations. A range of antibiotics can be useful against these bacteria including tetracyclines, co-trimoxazole, colistin, and piperacillin/tazobactam. There are no eradication studies in the people infected with these bacteria, but it is logical to attempt to clear these organisms if possible. Inhaled colistin can be used for $S$. maltophilia infection, and combinations of the above antibiotics can be used for treatment of exacerbations (Döring et al. 2012).

\section{B. cepacia Complex Strains}

Treatment of B. cepacia complex strains is quite problematic. In general, members of this complex have intrinsic antibiotic resistance, and Burkholderia cenocepacia, which historically has been the most common Burkholderia in people with CF, is almost universally pan-resistant. There are no long-term antibiotics recommended for treatment of patients with chronic infection with $B$. cepacia complex strains, and a 
Antibiotics and Anti-Inflammatories in CF

recent study of inhaled aztreonam lysine showed no benefit. Intravenous antibiotic treatment is based on several studies that would suggest that tetracycline, co-trimoxazole, chloramphenicol, colistin, ceftazidime, meropenem, and piperacillin/tazobactam combinations may have clinical efficacy (Döring et al. 2012).

\section{Nontuberculous Mycobacterial Infection}

Nontuberculous mycobacterial infection is a currently emerging area that is causing diagnostic and therapeutic challenges. Several nontuberculous mycobacteria have been isolated from people with CF, although the predominant groups are the Mycobacterium avium complex and Mycobacterium abscessus organisms. M. abscessus infection in CF and in other chronic lung conditions is associated with particular challenges (Döring et al. 2012). Treatment for both organisms requires long-term therapy with combinations of oral, intravenous and/or inhaled antimycobacterial agents. Mycobacterium avium complex organisms are typically treated with combinations of ethambutol, rifampin, macrolides, and inhaled amikacin. For $\mathrm{Myco}$ bacterium abscessus, combinations of amikacin, linezolid, macrolides, cefoxitin, tigicycline, and/ or meropenem are utilized. Currently, international guidelines are being developed to help further guide treatment of this difficult group of bacteria.

\section{Other Bacterial Species}

Many other bacterial species are being identified in the airway microbiota in people with CF. Treatment of organisms such as Streptococcus species and anaerobic bacteria such as Prevotella, Veillonella, Rothia, and Actinomyces species is not clear (Tunney et al. 2011; Zhao et al. 2012). There may be changes in how we perceive treatment with antibiotics over the next several years because second-generation sequencing provides more insight into the complex microbiota of the airways in people with CF. Antimicrobial therapy remains a key cornerstone for the modulation of infection and inflammation in CF.

\section{THERAPIES DIRECTED AT THE INFLAMMATORY RESPONSE OF THE CF AIRWAY}

Addressing the inflammatory response is warranted because it is the major process leading to lung destruction. Several steps in the pathophysiological cascade could be targeted. However, efficacy at any step may be beneficial. Early anti-inflammatory drug studies focused on systemic and inhaled corticosteroids, ibuprofen, and other nonsteroidal anti-inflammatory drugs (NSAIDs). Many anti-inflammatory drugs have been studied in CF since 1990. Although many have been translated from the bench to a clinical trial, precious few are recommended for clinical use (Table 2). The length of this review precludes a detailed discussion of all of these drugs. This review focuses on drugs that have undergone in-depth evaluation or more recent developments. Corticosteroids and ibuprofen are reviewed first, followed by cytokines and anticytokines, modulators of intracellular signaling, antioxidants, protease inhibitors, and other anti-inflammatory therapies.

\section{CORTICOSTEROIDS}

Corticosteroids were the first anti-inflammatory drugs studied in CF. They reduce the formation of mucus and edema; inhibit chemotaxis, adhesion, and activation of leukocytes; inhibit NF$\kappa \mathrm{B}$ activation; and interfere with the synthesis or actions of inflammatory mediators. Several studies evaluated corticosteroids as a chronic therapy for attenuating CF airway inflammation. Two 4-yr, double-blind, placebo-controlled studies of oral corticosteroids laid the foundation for future anti-inflammatory trials (Auerbach et al. 1985; Eigen et al. 1995). In these studies, alternate-day corticosteroids were associated with better lung function, improved weight gain, and fewer hospital admissions. In one trial, beneficial effects on lung function were observed primarily in patients infected with P. aeruginosa (Eigen et al. 1995). Adverse effects, including glucose intolerance, growth impairment, and cataract formation, limit the longterm practical application of alternate-day oral 
J.F. Chmiel et al.

Table 2. Anti-inflammatory therapies evaluated in CF

\begin{tabular}{|c|c|}
\hline Therapy & Target \\
\hline \multicolumn{2}{|l|}{ Evaluated only in preclinical studies } \\
\hline Anti-ICAM-1 & Leukocyte adhesion molecules \\
\hline Anti-IL-8 & Cytokines \\
\hline Anti-IL-17 & Cytokines \\
\hline IL-10 & Intracellular signaling and cytokines \\
\hline Interferon- $\gamma$ & Intracellular signaling \\
\hline $\begin{array}{l}\text { p38 Mitogen-activated protein } \\
\text { kinase inhibitors }\end{array}$ & Intracellular signaling \\
\hline \multicolumn{2}{|l|}{ Evaluated in clinical trials } \\
\hline$\alpha 1$-Protease inhibitor & Proteases \\
\hline Corticosteroids & $\begin{array}{l}\text { Intracellular signaling, eiscosanoids, } \\
\text { cytokines }\end{array}$ \\
\hline CXCR2 antagonist & Neutrophil chemotaxis/activation \\
\hline Cyclosporine-A & Intracellular signaling \\
\hline DHA & Eicosanoid modulator \\
\hline EPI-hNE4 & Proteases \\
\hline Glutathione & Oxidants \\
\hline Hydroxychloroquine & Unknown \\
\hline L-Arginine & Intracellular signaling \\
\hline $\mathrm{LTB}_{4}$ receptor antagonist (BIIL $284 \mathrm{BS}$ ) & Leukotriene receptors, eicosanoids \\
\hline Methotrexate & $\begin{array}{l}\text { Adhesion molecules, cytokines, transmethylation } \\
\text { reactions, increases adenosine release }\end{array}$ \\
\hline Monocyte/neutrophil elastase inhibitor & Proteases \\
\hline Montelukast & Leukotriene receptors \\
\hline$N$-Acetyl cysteine & Intracellular signaling, oxidants \\
\hline Omega-3-fatty acids & Eicosanoids \\
\hline Secretory leukoprotease inhibitor & Proteases \\
\hline Simvastatin & Intracellular signaling \\
\hline Thiazolidinediones/pioglitazone & Intracellular signaling \\
\hline Vitamins $C, E$, and $\beta$-carotene & Oxidants \\
\hline Vitamin D & Bacteria and cytokines \\
\hline \multicolumn{2}{|l|}{ Therapies recommended for clinical use } \\
\hline Antibiotics & Bacteria (inflammatory stimuli) \\
\hline Azithromycin & Unknown \\
\hline Dornase-alfa & DNA \\
\hline Ibuprofen & Intracellular signaling, eicosanoids, cytokines \\
\hline
\end{tabular}

corticosteroids. In a follow-up study, growth deficits persisted after therapy discontinuation (Lai et al. 2000). In view of these results and other known toxicities of corticosteroids including osteopenia, osteoporosis, and skeletal muscle weakness, the long-term use of systemic corticosteroids for slowing lung function decline is not advocated (Flume et al. 2007).

Adverse effects associated with systemic corticosteroids prompted investigations of inhaled corticosteroids (ICS). The inhaled route might afford benefit with less risk than systemic administration, but systemic administration may be necessary to affect neutrophil migration. Consistent ICS use was associated with a slower rate of decline of lung function. However, ICS use also was associated with decreased weight and height for age, and increased use of insulin and oral hypoglycemic agents in one large observational study (Ren et al. 2008). In another observational study, ICSs were associated with slower $\mathrm{FEV}_{1}$ decline in children with $\mathrm{CF}$ age 
$6-12$ yr but not other age groups (De Boeck et al. 2011). A benefit of ICS has not been shown in randomized placebo-clinical trials. None of the trials of ICS in CF showed convincing effects on lung function or airway inflammatory markers (Ross et al. 2009). Small study populations and short observation periods hampered these trials. In a large, prospective, multicenter study, withdrawal of ICS for a 6-mo period was not associated with significant worsening of CF lung disease (Balfour-Lynn et al. 2006). Patients in whom steroids were discontinued did not have worsening of lung function, an increased need for oral or intravenous antibiotics, or a shorter time to pulmonary exacerbation. Thus, although inhaled steroids may be of benefit in patients with coexisting asthma, their use as an anti-inflammatory agent in CF has not been substantiated. Potential long-term complications of ICS have not been adequately evaluated in CF. Caution should be heeded when prescribing ICS to patients with CF. A Cystic Fibrosis Foundation expert panel advised against the long-term use of ICS in patients with CF older than 6 yr who did not have coexistent asthma or allergic bronchopulmonary aspergillosis (ABPA) (Flume et al. 2007).

\section{IBUPROFEN}

NSAIDs possess properties similar to corticosteroids but have fewer adverse effects. Ibuprofen has received the most attention in CF, largely because it has specific activity against neutrophils. Neutrophil chemotaxis to mucosal epithelium is significantly decreased with oral doses of ibuprofen that result in a peak plasma concentration $>50 \mu \mathrm{g} / \mathrm{mL}$ (Konstan et al. 2003). In a 4-yr, double-blind, placebo-controlled clinical trial in the United States in patients with CF, twice-daily high-dose ibuprofen was associated with a slower rate of decline in pulmonary function measures, better preservation of body weight, fewer hospital admissions, and better Brasfield chest radiograph scores, with no significant adverse effects (Konstan et al. 1995). The beneficial effects were most pronounced in the youngest patients (5-13 yr old). A 2-yr placebo-controlled multicenter trial in Canada in
145 CF children also showed a beneficial effect of ibuprofen on lung function (Lands et al. 2007). Results from an analysis of observational data from the CF Foundation Patient Registry revealed that "real world" clinical use of ibuprofen in 1365 CF children treated on average for $4 \mathrm{yr}$ reduced the annual rate of $\mathrm{FEV}_{1}$ decline by $29 \%$ compared with those not treated with ibuprofen (Konstan et al. 2007).

Nonetheless, ibuprofen has not been widely adopted, largely because of the logistic challenges associated with the need to establish the dose in each patient with a 3 -h pharmacokinetic test and to concerns related to adverse effects of the drug (Konstan 2008). Based on U.S. CF Foundation Patient Registry data, ibuprofen use is associated with gastrointestinal bleeding, but the occurrence is rare (annual incidence $0.37 \%$ vs. $0.14 \%$ in those not treated with ibuprofen [Konstan et al. 2007]). Concomitant use of antacids, proton pump inhibitors, or misoprostol (a $\mathrm{PGE}_{1}$ analog) would likely limit this adverse event. Renal failure associated with ibuprofen therapy has been the subject of a few case reports, but CF Foundation Registry data suggest that the incidence of renal failure is not increased among CF patients treated with ibuprofen (Konstan et al. 2007). Thus, the benefits of this therapy appear to outweigh the associated risks. An expert panel recommended high-dose ibuprofen for CF patients with mild lung disease (Flume et al. 2007). A Cochrane Review also concluded that "high-dose ibuprofen can slow the progression of lung disease in people with CF, especially in children, and this suggests that strategies to modulate lung inflammation can be beneficial for people with CF" (Lands and Stanojevic 2007).

\section{CYTOKINES AND ANTICYTOKINES}

Since the first trial of corticosteroids, many new anti-inflammatory drugs have been introduced for the treatment of other diseases. Anti-inflammatory cytokines and antibodies to proinflammatory cytokines may have efficacy in CF. Most cytokines are pleiomorphic, and although some show a preponderance of proinflammatory effects, others show a preponderance of 
J.F. Chmiel et al.

anti-inflammatory effects. IL-10 possesses many anti-inflammatory properties. It inhibits the production of many proinflammatory cytokines, inhibits NF- $\mathrm{KB}$ activation, induces neutrophil apoptosis, and decreases antigen presentation and T-cell stimulation. Because IL-10 terminates the inflammatory response, its deficiency, as shown in CF (Bonfield et al. 1999), might result in persistent inflammation even after stimulus removal. IL-10 deficiency worsens endobronchial inflammation in $P$. aeruginosainfected mice (Chmiel et al. 2002b). Administration of IL-10 to infected mice showed beneficial effects on airway inflammation (Chmiel et al. 1999). A planned clinical trial of the drug was abandoned for reasons unrelated to $\mathrm{CF}$, but this remains an interesting therapeutic option. Interferon- $\gamma$, another cytokine with anti-inflammatory effects, did not improve pulmonary function or alter sputum inflammatory mediators in a multicenter clinical trial despite its ability to restore counter-regulatory functions in CF cell models (Moss et al. 2005).

An alternative approach to administering anti-inflammatory cytokines would be to inhibit specific proinflammatory mediators. Antibodies to ICAM-1 and IL- 8 have been evaluated in preclinical studies but never came to fruition in clinical trials. IL-17, a proinflammatory cytokine involved in TH-17 cell signaling, is elevated in CF lungs (McAllister et al. 2005; Dubin and Kolls 2007) and plays an important role in recruiting neutrophils to the airway in response to infectious stimuli. Anti-IL-17 antibodies reduced airway neutrophilia in mice exposed to lipopolysaccharide (LPS) (Ferretti et al. 2003). Clinical trials of anti-IL-17 in rheumatoid arthritis and psoriasis recently have been completed. Given the similarities between CF lung inflammation and these hyperinflammatory conditions, anti-IL-17 could be considered for CF.

\section{EICOSANOID MODULATORS}

$\mathrm{LTB}_{4}$, a potent neutrophil chemoattractant, is present in high concentrations in the CF airway (Konstan et al. 1993). BIIL 284 BS (amelubant), a specific $\mathrm{LTB}_{4}$ receptor antagonist, was studied in CF, but the trial was terminated early because of a statistically significant increase in pulmonary-related serious adverse events in adults receiving BIIL 284 BS (Konstan et al. 2005). One possible explanation is that $\mathrm{LTB}_{4}$ has some other previously unrecognized beneficial effect in $\mathrm{CF}$, and its inhibition is detrimental. A more plausible explanation might be that the inhibitory effect of BIIL 284 BS on the $\mathrm{LTB}_{4}$ pathway was too potent, resulting in impaired antimicrobial defenses and increasing the risk of an exacerbation. Regardless, the results of this study show that care must be taken when selecting an antiinflammatory agent for future clinical trials.

Deficiencies in some fatty acids may contribute to CF pulmonary inflammation. There is an increase in arachidonic acid and a decrease in docosahexaenoic acid (DHA) in $\mathrm{cftr}^{-/}$mice (Freedman et al. 1999). Investigators have shown that oral administration of DHA to $c \mathrm{ftr}^{-/}$mice corrected the lipid imbalance and reversed the observed pathological manifestations (Freedman et al. 2002; Beharry et al. 2007). There have been a handful of studies of DHA supplementation in CF patients (Van Biervliet et al. 2008; Aldamiz-Echevarria et al. 2009). Unfortunately, the dose of DHA, study size, duration of treatment, and outcome measures vary widely. Few are placebo-controlled, and some do not show a clinical effect on lung function, possibly because of short observational periods. Despite these drawbacks, the cumulative data from these studies indicate that DHA oral supplementation may effectively increase serum and phospholipid concentrations of this essential fatty acid, and that this may have beneficial health effects, including improved pulmonary function. To validate this claim, larger, placebo-controlled trials with an adequate observation period are necessary.

\section{MODULATORS OF INTRACELLULAR SIGNALING}

Because cytokines contribute to the excessive inflammatory response in CF, it seems logical to target signaling pathways responsible for upregulating their production. Unfortunately, there is no consensus as to what these pathways are and how they may interact with the basic defect in CF. High-dose ibuprofen and IL-10 
inhibit NF- $\mathrm{BB}$ activation, thereby down-regulating the inflammatory response at the transcriptional level. Other drugs that limit proinflammatory molecule transcription may be useful in CF. Another mechanism of inhibiting NF- $\kappa$ B activity occurs via up-regulation of peroxisome proliferator activating receptor (PPAR) with the thiazolidinediones or glitazones (Ruan et al. 2003; Vanden Berghe et al. 2003; Zingarelli et al. 2003). CF tissues appear to be deficient in PPAR (Ollero et al. 2004; Perez et al. 2008). Decreased PPAR expression leads to an im-

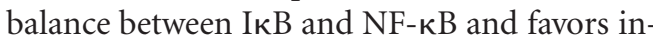
creased inflammation. Activation of PPAR may quell the CF inflammatory response. One of the mechanisms by which ibuprofen may work in $\mathrm{CF}$ is through the inhibition of NF- $\mathrm{KB}$ by activating PPAR $\gamma$ (Jaradat et al. 2001; Davis et al. 2003). Troglitazone and ciglitazone activate PPAR in primary CF airway epithelial cells and CF epithelial cell lines, and reduce production of proinflammatory mediators in response to P. aeruginosa (Perez et al. 2008). A 28-d clinical trial of pioglitazone did not show a beneficial effect on sputum inflammatory mediators (Konstan et al. 2009). However, this may have occurred because the dose of pioglitazone was not adequate to inhibit inflammation, the duration of the study was too short, the number of subjects was too small $(N=20)$, or sputum measures may not have been sensitive enough to detect subtle changes. Although this study did not show a beneficial effect, further evaluation of the glitazones in CF is warranted.

Multiple studies show decreased $\mathrm{NO}$ in exhaled air (eNO) from patients with CF (BalfourLynn et al. 1996; Grasemann et al. 1997). NO is a highly reactive molecule with important antimicrobial and anti-inflammatory properties. The loss of NO production from the airways may contribute to bacterial infection and overzealous inflammation (Kelley and Drumm 1998; Meng et al. 1998). One potential cause of decreased eNO in CF is up-regulation of RhoGTPase, a signaling molecule that reduces NOS2 expression (Kraynack et al. 2002). Up-regulation of RhoGTPase may also contribute to the inflammatory response by increasing IL- 8 production. RhoGTPase can be inhibited by block- ing 3-hydroxy-3-methylglutaryl-CoA reductase (HMG-CoAR) with the commercially available statins (e.g., simvastatin) (Kraynack et al. 2002). The statins have other anti-inflammatory effects including the ability to inhibit neutrophil migration, decrease proinflammatory cytokine production, and increase transcriptional activation of PPAR (Dunzendorfer et al. 1997; RezaieMajd et al. 2002; Zelvyte et al. 2002). A clinical trial of simvastatin showed a trend toward increased eNO, but no effect was seen on sputum inflammatory markers. This may be for the same reasons cited above for pioglitazone (Kraynack et al. 2008). Other agents that increase NO production have also been studied. Arginase activity is increased in blood and sputum of CF patients and may further decrease NO by degrading L-arginine, an NO substrate (Grasemann et al. 2005a). In a rodent model, L-arginine was associated with reduced tissue damage, decreased neutrophil recruitment, and reduced IL- $1 \beta$ (Hopkins et al. 2006). A small study of L-arginine in $\mathrm{CF}$ was associated with increased eNO (Grasemann et al. 2005b). L-Arginine has potential, but large prospective clinical trials have not been performed.

Synthetic triterpenoids are small-molecule derivatives of naturally occurring compounds that increase Nrf2 activity. Nrf2, a transcription factor active in respiratory epithelia and pivotal to mitigating the acute inflammatory response, is deficient in CF cells (Chen et al. 2008; Nichols et al. 2009). Small molecules like the synthetic triterpenoids that target proinflammatory signaling abnormalities in CF cells may be candidates for clinical trials. Preclinical studies show the ability of 2-cyano-3,12-dioxooleana-1,9dien-28-oic acid (CDDO) to reduce the inflammatory response (Nichols et al. 2009). Much research is still needed to determine their utility, but early data suggest the theory that compounds affecting transcriptional regulators of inflammation (both pro- and anti-inflammatory) are promising therapeutic agents.

\section{ANTIOXIDANTS}

Neutrophils release oxygen radicals that contribute to local tissue damage and perpetuate 
J.F. Chmiel et al.

inflammation. Elevated concentrations of oxidants have been detected in the airways of CF mice and patients (Hull et al. 1997; Velsor et al. 2001). The oxidant-antioxidant imbalance contributes to the exaggerated and damaging inflammatory response. Some biochemical abnormalities in CF can be reversed by antioxidants. $N$-Acetyl cysteine, initially developed as a mucolytic, is receiving renewed interest as an antioxidant that both inhibits $\mathrm{H}_{2} \mathrm{O}_{2}$ and increases glutathione. In a pilot study, oral $\mathrm{N}$ acetyl cysteine was associated with increased glutathione levels in whole blood and decreased sputum neutrophils, IL-8, and elastase activity (Tirouvanziam et al. 2006). The study was of short duration and not powered to detect changes in pulmonary function or other clinical outcome measures. A large randomized doubleblind placebo-controlled trial of $\mathrm{N}$-acetyl cysteine is ongoing in patients with CF.

The oxidant-antioxidant imbalance may be exacerbated by abnormalities in CFTR. If glutathione is transported by CFTR (Linsdell and Hanrahan 1998), then CFTR abnormalities would decrease the concentrations of this important antioxidant on epithelial surfaces, thus leaving the airway vulnerable to even ordinary levels of oxidative stress. Because decreased lung concentrations of glutathione have been shown in CF mice and patients (Roum et al. 1993; Velsor et al. 2001), it seems logical to augment its concentration in the CF lung. Glutathione in epithelial lining fluid may be increased by twice-daily treatment with aerosolized glutathione. This treatment also reduced superoxide production by inflammatory cells (Roum et al. 1993). However, subjects treated with inhaled glutathione had no detectable change in BAL markers of oxidative stress (Bishop et al. 2005; Hartl 2005). Inhaled glutathione therapy for CF has attracted much attention, but its therapeutic benefit has not been adequately studied.

\section{PROTEASE INHIBITORS}

Early in life, neutrophils infiltrate the CF airway and release massive amounts of proteases that overwhelm antiproteases, including alpha-1protease inhibitor $\left(\alpha_{1}-\mathrm{PI}\right)$ and secretory leuko- cyte protease inhibitor (SLPI). The concentration of $\alpha_{1}$-PI in BAL fluid from CF patients is several-fold higher than in healthy subjects, but even in mild patients there is a several hundred to several thousand fold excess of elastase and other neutrophil proteases, which vastly exceeds the capacity of the inhibitors (Birrer et al. 1994; Konstan et al. 1994; Chmiel et al. 2002a). The imbalance between the proteases and their inhibitors becomes worse during exacerbations and undoubtedly results in airway injury. Antiproteases have been under investigation in CF since 1990. Aerosol delivery of $\alpha_{1}$-antitrypsin suppressed inflammatory markers including free neutrophil elastase, proinflammatory cytokines, and neutrophils (McElvaney et al. 1991; Berger et al. 1995; Bilton et al. 1999; Griese et al. 2007). Other inhibitors of neutrophil elastase studied in CF include rSLPI and the small-molecule drug EPI-hNE4 (McElvaney et al. 1993; Grimbert et al. 2003). Although these inhibitors showed positive effects in CF, further trials have not been conducted with these inhibitors. Data regarding antiprotease therapy suggest that antiprotease therapy possesses the potential to impact CF inflammation. Of the antiprotease therapies studied in CF, inhalation of plasmaderived $\alpha_{1}$-antitrypsin appears closest to possible clinical use.

\section{OTHER THERAPIES THAT IMPACT INFLAMMATION IN THE CF AIRWAY}

Hydroxychloroquine, a dihydrofolate reductase inhibitor that increases intracellular $\mathrm{pH}$ and possesses anecdotal efficacy in some rare interstitial lung diseases, was evaluated in a small 28-d study in CF (Williams et al. 2008). The drug was well tolerated, but there was no change in sputum inflammatory markers (Williams et al. 2008). CXCR2 is an important receptor in neutrophil chemotaxis. Clinical and preclinical studies have evaluated the effects of CXCR2 antagonists in many lung diseases including COPD, asthma, and ozone-induced airway inflammation (Lazaar et al. 2011). A clinical trial in CF of SB-656933, a CXCR2 antagonist, was recently completed and shows some promise in modulating airway inflammation (Moss et al. 
2012). Although chemotherapeutics have been studied in refractory asthma, there have been few studies in CF. Low-dose cyclosporin A decreased the need for systemic corticosteroids in one small case series (Bhal et al. 2001). In a small pilot study, methotrexate increased $\mathrm{FEV}_{1}$ and decreased total serum immunoglobulins in five CF patients after $1 \mathrm{yr}$ of treatment (Ballmann et al. 2003). However, in a more recent study, methotrexate was not well tolerated and was associated with an increased need for IV antibiotics (Oermann et al. 2007). Its routine use cannot be advocated. Because of toxicities, chemotherapeutics should be studied first in animal models. However, even if toxic, some agents may have a favorable risk/benefit profile.

\section{CONCLUSION}

CF lung disease begins early in infancy and continues unabated. Persistent infection and excessive inflammation are key contributors to the progression of CF lung disease. Studies showed that judicious use of antibiotics and anti-inflammatory drugs is beneficial. The development of both systemic and inhaled antibiotics has greatly improved survival and remains a cornerstone therapy. With the wider range of antibiotics now available, it is important that the most effective regimes for chronic therapy, which reduce pulmonary exacerbations, be determined. It is also critical that pulmonary exacerbations be identified early and treated with appropriate antibiotic combinations.

Anti-inflammatory drugs are another important weapon in the fight against CF. Although ICSs are the most frequently prescribed anti-inflammatory therapy in CF, their benefits, like their risks, have not been fully established. Thus far, high-dose chronic ibuprofen treatment is the best-proven anti-inflammatory drug, although its use in the CF community has been surprisingly low. Newer anti-inflammatory agents will probably come to clinical trial over the next few years. More studies of anti-inflammatory agents are necessary to fully elucidate their mechanisms of action, to determine which would provide the most benefit to CF patients, and to establish the optimal patient age and stage of lung disease for initiation of treatment.

Drugs designed to target abnormal CFTR may not fully ameliorate the relentless progression of CF lung disease in patients with established bronchiectasis. Therefore, vigorous research and development into anti-infective and anti-inflammatory therapeutics that address secondary disease pathology must continue. Improved antibacterial and anti-inflammatory therapies should lessen morbidity, improve quality of life, and prolong survival.

\section{ACKNOWLEDGMENTS}

Grant support from the National Institutes of Health (Grant P30-DK27651) and the U.S. Cystic Fibrosis Foundation is gratefully acknowledged. We gratefully acknowledge the editorial assistance of Robert C. Stern, M.D.

\section{REFERENCES}

Aldámiz-Echevarría L, Prieto JA, Andrade F, Elorz J, Sojo A, Lage S, Sanjurjo P, Vázquez C, Rodríguez-Soriano J. 2009. Persistence of essential fatty acid deficiency in cystic fibrosis despite nutritional therapy. Pediatr Res 66: 585589.

Armstrong DS, Grimwood K, Carzino R, Carlin JB, Olinsky A, Phelan PD. 1995. Lower respiratory infection and inflammation in infants with newly diagnosed cystic fibrosis. BMJ 310: 1571-1572.

Armstrong DS, Grimwood K, Carlin JB, Armstrong DS, Grimwood K, Carlin JB, Carzino R, Gutièrrez JP, Hull J, Olinsky A, et al. 1997. Lower airway inflammation in infants and young children with cystic fibrosis. Am J Respir Crit Care Med 156: 1197-1204.

Auerbach HS, Williams M, Kirkpatrick JA, Colten HR. 1985. Alternate-day prednisone reduces morbidity and improves pulmonary function in cystic fibrosis. Lancet 2: 686-688.

Balfour-Lynn IM, Laverty A, Dinwiddie R. 1996. Reduced upper airway nitric oxide in cystic fibrosis. Arch Dis Child 75: 319-322.

Balfour-Lynn IM, Lees B, Hall P, Phillips G, Khan M, Flather M, Elborn JS, CF WISE (Withdrawal of Inhaled Steroids Evaluation) Investigators. 2006. Multicenter randomized controlled trial of withdrawal of inhaled corticosteroids in cystic fibrosis. Am J Respir Crit Care Med 173: $1356-1362$.

Ballmann M, Junge S, von der Hardt H. 2003. Low-dose methotrexate for advanced pulmonary disease in patients with cystic fibrosis. Respir Med 97: 498-500.

Balough K, McCubbin M, Weinberger M, Smits W, Ahrens R, Fick R. 1995. The relationship between infection 
J.F. Chmiel et al.

and inflammation in the early stages of lung disease from cystic fibrosis. Pediatr Pulmonol 20: 63-70.

Beharry S, Ackerley C, Corey M, Kent G, Heng YM, Christensen H, Luk C, Yantiss RK, Nasser IA, Zaman M, et al. 2007. Long-term docosahexaenoic acid therapy in a congenic murine model of cystic fibrosis. Am J Physiol Gastrointest Liver Physiol 292: G839-G848.

Berger M, Konstan MW, Hilliard JB. 1995. Aerosolized prolastin $\left(\alpha_{1}\right.$-protease inhibitor) in CF. Pediatr Pulmonol 20: 421.

Bhal GK, Maguire SA, Bowler IM. 2001. Use of cyclosporin A as a steroid sparing agent in cystic fibrosis. Arch Dis Child 84: 89.

Bilton D, Elborn S, Conway S, Edgar J, Redmond A. 1999. Phase II trial to assess the clinical efficacy of transgenic $\alpha$ 1-antitrypsin (tg-hAAT) as an effective treatment of cystic fibrosis. Pediatr Pulmonol 28 (Suppl 19): 246.

Birrer P, McElvaney NG, Rüdeberg A, Sommer CW, LiechtiGallati S, Kraemer R, Hubbard R, Crystal RG. 1994. Protease-antiprotease imbalance in the lungs of children with cystic fibrosis. Am J Respir Crit Care Med 150: 207 213.

Bishop C, Hudson VM, Hilton SC, Wilde C. 2005. A pilot study of the effects of inhaled buffered reduced glutathione on the clinical status of patients with cystic fibrosis. Chest 127: 308-317.

Bonfield TL, Panuska JR, Konstan MW, Hilliard KA, Hilliard JB, Ghnaim H, Berger M. 1995a. Inflammatory cytokines in cystic fibrosis lungs. Am J Respir Crit Care Med 152: $2111-2118$

Bonfield TL, Konstan MW, Burfeind P, Panuska JR, Hilliard JB, Berger M. 1995b. Normal bronchial epithelial cells constitutively produce the anti-inflammatory cytokine interleukin-10, which is downregulated in cystic fibrosis. Am J Respir Cell Mol Biol 13: 257-261.

Bonfield TL, Konstan MW, Berger M. 1999. Altered respiratory epithelial cell cytokine production in cystic fibrosis J Allergy Clin Immunol 104: 72-78.

Chen J, Kinter M, Shank S, Cotton C, Kelley TJ, Ziady AG. 2008. Dysfunction of Nrf-2 in CF epithelia leads to excess intracellular $\mathrm{H}_{2} \mathrm{O}_{2}$ and inflammatory cytokine production. PLoS ONE 3: e3367.

Chmiel JF, Davis PB. 2003. State of the art: Why do the lungs of patients with cystic fibrosis become infected and why can't they clear the infection? Respir Res 4: 8-21.

Chmiel JF, Konstan MW, Knesebeck JE, Hilliard JB, Bonfield TL, Dawson DV, Berger M. 1999. IL-10 attenuates excessive inflammation in chronic Pseudomonas infection in mice. Am J Respir Crit Care Med 160: $2040-$ 2047.

Chmiel JF, Konstan MW, Berger M. 2002a. The role of inflammation in the pathophysiology of CF lung disease. Clin Review Allergy Immunol 23: 5-27.

Chmiel JF, Konstan MW, Saadane A, Krenicky JE, Lester Kirchner H, Berger M. 2002b. Prolonged inflammatory response to acute Pseudomonas challenge in interleukin10 knockout mice. Am J Respir Crit Care Med 165: 1176 1181.

Dasenbrook EC, Merlo CA, Diener-West M, Lechtzin N, Boyle MP. 2008. Persistent methicillin-resistant Staphylo- coccus aureus and rate of FEV1 decline in cystic fibrosis. Am J Respir Crit Care Med 178: 814-821.

Dasenbrook EC, Checkley W, Merlo CA, Konstan MW, Lechtzin N, Boyle MP. 2010. Association between respiratory tract methicillin-resistant Staphylococcus aureus and survival in cystic fibrosis. JAMA 303: 2386-2392.

Davis PB, Drumm M, Konstan MW. 1996. Cystic fibrosis. State of the art. Am J Resp Crit Care Med 154: 1229-1256.

Davis PB, Gupta S, Eastman J, Konstan MW. 2003. Inhibition of proinflammatory cytokine production by PPAR $\gamma$ agonists in airway epithelial cells. Pediatr Pulmonol 36 (Suppl 25): 268-269.

De Boeck K, Vermeulen F, Wanyama S, Thomas M, Members of the Belgian CF Registry. 2011. Inhaled corticosteroids and lower lung function decline in young children with cystic fibrosis. Eur Respir J 37: 1091-1095.

Döring G, Flume P, Heijerman H, Elborn JS, Consensus Study Group. 2012. Treatment of lung infection in patients with cystic fibrosis: Current and future strategies. $J$ Cyst Fibros 2012 11: 461-479.

Dubin PJ, Kolls JK. 2007. IL-23 mediates inflammatory responses to mucoid Pseudomonas aeruginosa lung infection in mice. Am J Physiol Lung Cell Mol Physiol 292: L519-L528.

Dubin PJ, McAllister F, Kolls JK. 2007. Is cystic fibrosis a TH17 disease? Inflamm Res 56: 221-227.

Dunzendorfer S, Rothbucher D, Schratzberger P, Reinisch N, Kahler CM, Wiedermann CJ. 1997. Mevalonate-dependent inhibition of transendothelial migration and chemotaxis of human peripheral blood neutrophils by pravastatin. Circ Res 81: 963-969.

Eigen H, Rosenstein BJ, FitzSimmons S, Schidlow DV. 1995. A multicenter study of alternate-day prednisone therapy in patients with cystic fibrosis. Cystic Fibrosis Foundation Prednisone Trial Group. J Pediatr 126: 515-523.

Ferretti S, Bonneau O, Dubois GR, Jones CE, Trifilieff A. 2003. IL-17, produced by lymphocytes and neutrophils, is necessary for lipopolysaccharide-induced airway neutrophilia: IL-15 as a possible trigger. J Immunol 170: 2106-2112.

Flume PA, O'Sullivan BP, Robinson KA, Goss CH, Mogayzel PJ Jr, Willey-Courand DB, Bujan J, Finder J, Lester M Quittell L, et al. 2007. Cystic fibrosis pulmonary guidelines. Am J Respir Crit Care Med 176: 957-969.

Freedman SD, Katz MH, Parker EM, Laposata M, Urman MY, Alvarez JG. 1999. A membrane lipid imbalance plays a role in the phenotypic expression of cystic fibrosis in $c \mathrm{fr}^{-/-}$mice. Proc Natl Acad Sci 96: 1399514000 .

Freedman SD, Weinstein D, Blanco PG, Martinez-Clark P, Urman S, Zaman M, Morrow JD, Alvarez JG. 2002. Characterization of LPS-induced lung inflammation in $c f t r^{-/-}$mice and the effect of docosahexaenoic acid. $J$ Appl Physiol 92: 2169-2176.

Grasemann H, Michler E, Wallot M, Ratjen F. 1997. Decreased concentration of exhaled nitric oxide (NO) in patients with cystic fibrosis. Pediatr Pulmonol 24: $173-$ 177.

Grasemann H, Schwiertz R, Matthiesen S, Racke K, Ratjen F. 2005a. Increased arginase activity in cystic fibrosis airways. Am J Respir Crit Care Med 172: 1523-1528. 
Grasemann H, Grasemann C, Kurtz F, Tietze-Schillings G, Vester U, Ratjen F. 2005b. Oral L-arginine supplementation in cystic fibrosis patients: A placebo-controlled study. Eur Respir J 25: 62-68.

Griese M, Latzin P, Kappler M, Weckerle K, Heinzlmaier T, Bernhardt T, Hartl D. 2007. $\alpha 1$-Antitrypsin inhalation reduces airway inflammation in cystic fibrosis patients. Eur Respir J 29: 240-250.

Grimbert D, Vecellio L, Delépine P, Attucci S, Boissinot E, Poncin A, Gauthier F, Valat C, Saudubray F, Antonioz P, et al. 2003. Characteristics of EPI-hNE4 aerosol: A new elastase inhibitor for treatment of cystic fibrosis. J Aerosol Med 16: 121-129.

Hartl D, Starosta V, Maier K, Beck-Speier I, Rebhan C, Becker BF, Latzin P, Fischer R, Ratjen F, Huber RM, et al. 2005. Inhaled glutathione decreases PGE2 and increases lymphocytes in cystic fibrosis lungs. Free Radic Biol Med 39: 463-472.

Hopkins N, Gunning Y, O'Croinin DF, Laffey JG, McLoughlin P. 2006. Anti-inflammatory effect of augmented nitric oxide production in chronic lung infection. $J$ Pathol 209: 198-205.

Hull J, Vervaart P, Grimwood K, Phelan P. 1997. Pulmonary oxidative stress response in young children with cystic fibrosis. Thorax 52: 557-560.

Jaradat MS, Wongsud B, Phornchirasilp S, Rangwala SM, Shams G, Sutton M, Romstedt KJ, Noonan DJ, Feller DR. 2001. Activation of peroxisome proliferators-activated receptor isoforms and inhibition of prostaglandin $\mathrm{H}_{2}$ synthases by ibuprofen, naproxen, and indomethacin. Biochem Pharmacol 62: 1587-1595.

Kelley TJ, Drumm ML. 1998. Inducible nitric oxide synthase expression is reduced in cystic fibrosis murine and human airway epithelial cells. J Clin Invest 102: 1200-1207.

Khan TZ, Wagener JS, Bost T, Martinez J, Accurso FJ, Riches DW. 1995. Early pulmonary inflammation in infants with cystic fibrosis. Am J Respir Crit Care Med 151: 1075-1082.

Kirchner KK, Wagener JS, Khan TZ, Copenhaver SC, Accurso FJ. 1996. Increased DNA levels in bronchoalveolar lavage fluid obtained from infants with cystic fibrosis. Am J Respir Crit Care Med 154: 1426-1429.

Konstan MW. 2008. Ibuprofen therapy for cystic fibrosis lung disease: Revisited. Curr Opin Pulm Med 14: 567573.

Konstan MW, Berger M. 1997. Current understanding of the inflammatory process in cystic fibrosis-Onset and etiology. Pediatr Pulmonol 24: 137-142.

Konstan MW, Walenga RW, Hilliard KA, Hilliard JB. 1993. Leukotriene B4 is markedly elevated in the epithelial lining fluid of patients with cystic fibrosis. Am Rev Respir Dis 148: 896-901.

Konstan MW, Hilliard KA, Norvell TM, Berger M. 1994. Bronchoalveolar lavage findings in cystic fibrosis patients with stable, clinically mild lung disease suggest ongoing infection and inflammation. Am J Respir Crit Care Med 150: $448-454$.

Konstan MW, Byard PJ, Hoppel CL, Davis PB. 1995. Effect of high-dose ibuprofen in patients with cystic fibrosis. $N$ Engl J Med 332: 848-854.
Konstan MW, Krenicky JE, Finney MR, Kirchner HL, Hilliard KA, Hilliard JB, Davis PB, Hoppel CL. 2003. Effect of ibuprofen on neutrophil migration in vivo in cystic fibrosis. J Pharmacol Exp Ther 306: 1086-1091.

Konstan MW, Doring G, Lands LC, Hilliard KA, Koker P, Bhattacharya S, Staab A, Hamilton AL. 2005. Results of a phase II clinical trial of BIIL 284 BS (a LTB $_{4}$ receptor antagonist) for the treatment of CF lung disease. Pediatr Pulmonol 40 (Suppl 28): 125-127.

Konstan MW, Schluchter MD, Xue W, Davis PB. 2007. Clinical use of ibuprofen is associated with slower FEV1 decline in children with cystic fibrosis. Am J Respir Crit Care Med 176: 1084-1089.

Konstan M, Krenicky J, Hilliard K, Hilliard J. 2009. A pilot study evaluating the effect of pioglitazone, simvastatin, and ibuprofen on neutrophil migration in vivo in healthy subjects. Pediatr Pulmonol 44 (Suppl 32): 289-290.

Konstan MW, Geller DE, Minić P, Brockhaus F, Zhang J, Angyalosi G. 2011. Tobramycin inhalation powder for P. aeruginosa infection in cystic fibrosis: The EVOLVE trial. Pediatr Pulmonol 46: 230-238.

Kraynack NC, Corey DA, Elmer HL, Kelley TJ. 2002. Mechanisms of NOS2 regulation by Rho GTPase signaling in airway epithelial cells. Am J Physiol Lung Cell Mol Physiol 283: L604-L611.

Kraynack NC, Chmiel JF, Xue W, Schluchter MD, Gibson RL, Kelley TJ, Hilliard JB, Konstan MW. 2008. Effect of simvastatin on exhaled nitric oxide and inflammatory markers in sputum in patients with cystic fibrosis. Pediatr Pulmonol 43 (Suppl 31): 300.

Lai H-C, FitzSimmons SC, Allen DB, Kosorok MR, Rosenstein BJ, Campbell PW, Farrell PM. 2000. Risk of persistent growth impairment after alternate-day prednisone treatment in children with cystic fibrosis. $N$ Engl J Med 342: 851-859.

Lands L, Stanojevic S. 2007. Oral non-steroidal anti-inflammatory drug therapy for cystic fibrosis. Cochrane Database Syst Rev 17: CD001505.

Lands LC, Milner R, Cantin AM, Manson D, Corey M. 2007. High-dose ibuprofen in cystic fibrosis: Canadian safety and effectiveness trial. J Pediatr 151: 228-230.

Lazaar AL, Sweeney LE, MacDonald AJ, Alexis NE, Chen C, Tal-Singer R. 2011. SB-656933, a novel CXCR2 selective antagonist, inhibits ex vivo neutrophil activation and ozone-induced airway inflammation in humans. $\mathrm{Br} \mathrm{J}$ Clin Pharmacol 72: 282-293.

Linsdell P, Hanrahan JW. 1998. Glutathione permeability of CFTR. Am J Physiol 275 (Pt 1): C323-C326.

LiPuma J. 2010. The changing microbial epidemiology in CF. Clin Microbiol Rev 23: 299-323.

LiPuma J. 2012. The new microbiology of cystic fibrosis: It takes a community. Thorax 67: 851-852.

McAllister F, Henry A, Kreindler JL, Dubin PJ, Ulrich L, Steele C, Finder JD, Pilewski JM, Carreno BM, Goldman SJ, et al. 2005. Role of IL-17A, IL-17F, and the IL17 receptor in regulating growth related oncogene- $\alpha$ and granulocyte colony-stimulating factor in bronchial epithelium: Implications for airway inflammation in cystic fibrosis. J Immunol 175: 404-412.

McElvaney NG, Hubbard RC, Birrer P, Chernick MS, Caplan DB, Frank MM, Crystal RG. 1991. Aerosol $\alpha 1$ - 
J.F. Chmiel et al.

antitrypsin treatment for cystic fibrosis. Lancet 337: 392-394.

McElvaney NG, Doujaiji B, Moan MJ, Burnham MR, Wu MC, Crystal RG. 1993. Pharmacokinetics of recombinant secretory leukoprotease inhibitor aerosolized to normals and individuals with cystic fibrosis. Am Rev Respir Dis 148 (Pt 1): 1056-1060.

Meng QH, Springall DR, Bishop AE, Morgan K, Evans TJ, Habib S, Gruenert DC, Gyi KM, Hodson ME, Yacoub MH, et al. 1998. Lack of inducible nitric oxide synthase in bronchial epithelium: A possible mechanism of susceptibility to infection in cystic fibrosis. J Pathol 184: 323-331.

Moss RB, Mayer-Hamblett N, Wagener J, Daines C, Hale K, Ahrens R, Gibson RL, Anderson P, Retsch-Bogart G Nasr SZ, et al. 2005. Randomized, double-blind, placebo-controlled, dose-escalating study of aerosolized interferon $\gamma-1 b$ in patients with mild to moderate cystic fibrosis lung disease. Pediatr Pulmonol 39: 209-218.

Moss RB, Mistry SJ, Konstan MW, Pilewski JM, Kerem E, Tal-Singer R, Lazaar AL, for the CF2110399 Investigators. 2012. Safety and early treatment effects of the CXCR2 antagonist SB-656933 in patients with cystic fibrosis. J Cyst Fibros pii: S1569-1993(12)00155-5

Muhlebach MS, PW Stewart, Leigh MW, Noah TL. 1999. Quantitation of inflammatory response to bacteria in young cystic fibrosis and control patients. Am J Respir Crit Care Med 160: 186-191.

Nichols DP, Ziady AG, Shank SL, Eastman JF, Davis PB. 2009. The triterpenoid CDDO limits inflammation in preclinical models of cystic fibrosis lung disease. Am J Physiol Lung Cell Mol Physiol 297: L828-L836.

Noah TL, Black HR, Cheng PW, Wood RE, Leigh MW. 1997. Nasal and bronchoalveolar lavage fluid cytokines in early cystic fibrosis. J Infect Dis 175: 638-647.

Oermann CM, Katz M, Wheeler C, Cumming S. 2007. A pilot study evaluating the potential use of low-dose methotrexate as an anti-inflammatory therapy for cystic fibrosis lung disease. Pediatr Pulmonol 42 (Suppl 30): 292 293.

Ollero M, Junaidi O, Zaman MM, Tzameli I, Ferrando AA, Andersson C, Blanco PG, Bialecki E, Freedman SD. 2004 Decreased expression of peroxisome proliferators activated receptor $\gamma$ in $c \mathrm{ftr}^{-/}$mice. J Cell Physiol 200: $235-$ 244.

Parkins MD, Rendall JC, Elborn JS. 2012. Incidence and risk factors for pulmonary exacerbation treatment failures in cystic fibrosis patients chronically infected with Pseudomonas aeruginosa. Chest 141: 485-493.

Perez A, van Heeckeren AM, Nichols D, Gupta S, Eastman JF, Davis PB. 2008. Peroxisome proliferator-activated receptor- $\gamma$ in cystic fibrosis lung epithelium. Am J Physiol Lung Cell Mol Physiol 295: L303-L313.

Proesmans M. 2013. Comparison of two treatment regimens for eradication of $P$. aeruginosa infection in children with cystic fibrosis. J Cyst Fibros 12: 29-34.

Ratjen F, Munck A, Kho P, Angyalosi G, ELITE Study Group. 2010. Treatment of early Pseudomonas aeruginosa infection in patients with cystic fibrosis: The ELITE trial. Tho$\operatorname{rax}$ 65: 286-291.

Ren CL, Pasta DJ, Rasouliyan L, Wagener JS, Konstan MW, Morgan WJ, Scientific Advisory Group the Investigators and Coordinators of the Epidemiologic Study of Cystic Fibrosis. 2008. Relationship between inhaled corticosteroid therapy and rate of lung function decline in children with cystic fibrosis. J Pediatr 153: 746-751.

Rezaie-Majd A, Maca T, Bucek RA, Valent P, Müller MR, Husslein P, Kashanipour A, Minar E, Baghestanian M. 2002. Simvastatin reduces expression of cytokines interleukin-6, interleukin-8, and monocyte chemoattractant protein-1 in circulating monocytes from hypercholesterolemic patients. Arterioscler Thromb Vasc Biol 22: $1194-$ 1199.

Ross KR, Chmiel JF, Konstan MW. 2009. The role of inhaled corticosteroids in the management of cystic fibrosis. Paediatr Drugs 11: 101-113.

Roum JH, Buhl R, McElvaney NG, Borok Z, Crystal RG. 1993. Systemic deficiency of glutathione in cystic fibrosis. J Appl Physiol 75: 2419-2424.

Ruan H, Pownall HJ, Lodish HF. 2003. Troglitazone antagonizes tumor necrosis factor- $\alpha$-induced reprogramming of adipocyte gene expression by inhibiting the transcriptional regulatory functions of NF-кB. J Biol Chem 278: 28181-28192.

Sanders DB, Bittner RC, Rosenfeld M, Hoffman LR, Redding GJ, Goss CH. 2010. Failure to recover to baseline pulmonary function after cystic fibrosis pulmonary exacerbation. Am J Respir Crit Care Med 182: 627-632.

Schuster A, Haliburn C, Döring G, Goldman MH, for the Freedom Study Group. 2012. Safety, efficacy and convenience of colistimethate sodium dry powder for inhalation (Colobreathe DPI) in cystic fibrosis patients: A randomised study. Thorax 68: 344-350.

Smyth A, Elborn JS. 2008. Exacerbations in cystic fibrosis: 3-Management. Thorax 63: 180-184.

Smyth AR, Walters S. 2012. Prophylactic anti-staphylococcal antibiotics for cystic fibrosis. Cochrane Database Syst Rev 12: CD001912. 23235585.

Stenbit AE, Flume PA. 2011. Pulmonary exacerbations in cystic fibrosis. Curr Opin Pulm Med 17: 442-447.

Taccetti G, Bianchini E, Cariani L, Buzzetti R, Costantini D, Trevisan F. 2012. Early antibiotic treatment for Pseudomonas aeruginosa eradication in patients with cystic fibrosis: A randomised multicentre study comparing two different protocols. Thorax 67: 853-859.

Tirouvanziam R, Conrad CK, Bottiglieri T, Herzenberg LA, Moss RB, Herzenberg LA. 2006. High-dose oral $N$-acetylcysteine, a glutathione prodrug, modulates inflammation in cystic fibrosis. Proc Natl Acad Sci 103: 4628-4633.

Treggiari MM, Retsch-Bogart G, Mayer-Hamblett N, Khan U, Kulich M, Kronmal R, Williams J, Hiatt P, Gibson RL, Spencer T, et al. 2011. Comparative efficacy and safety of 4 randomized regimens to treat early Pseudomonas aeruginosa infection in children with cystic fibrosis. Arch Pediatr Adolesc Med 165: 847-856.

Tunney MM, Field TR, Moriarty TF, Patrick S, Doering G, Muhlebach MS, Wolfgang MC, Boucher R, Gilpin DF, McDowell A, et al. 2008. Detection of anaerobic bacteria in high numbers in sputum from patients with cystic fibrosis. Am J Respir Crit Care Med 177: 995-1001.

Tunney MM, Klem ER, Fodor AA, Gilpin DF, Moriarty TF, McGrath SJ, Muhlebach MS, Boucher RC, Cardwell C, Doering G, et al. 2011. Use of culture and molecular analysis to determine the effect of antibiotic treatment 
on microbial community diversity and abundance during exacerbation in patients with cystic fibrosis. Thorax 66: $579-584$.

Valerius NH, Koch C, Høiby N. 1991. Prevention of chronic Pseudomonas aeruginosa colonisation in cystic fibrosis by early treatment. Lancet 338: 725-726.

Van Biervliet S, Devos M, Delhaye T, Van Biervliet JP, Robberecht E, Christophe A. 2008. Oral DHA supplementation in $\Delta \mathrm{F} 508$ homozygous cystic fibrosis patients. Prostaglandins Leukot Essent Fatty Acids 78: 109-115.

Vanden Berghe W, Vermeulen L, Delerive P, De Bosscher K, Staels B, Haegeman G. 2003. A paradigm for gene regulation: Inflammation, NF-кB, and PPAR. Adv Exp Med Biol 544: 181-196.

VanDevanter DR, O’Riordan MA, Blumer JL, Konstan MW. 2010. Assessing time to pulmonary function benefit following antibiotic treatment of acute cystic fibrosis exacerbations. Respir Res 11: 137.

Velsor LW, van Heeckeren A, Day BJ. 2001. Antioxidant imbalance in the lungs of cystic fibrosis transmembrane conductance regulator protein mutant mice. Am J Physiol Lung Cell Mol Physiol 281: L31-L38.
Williams HD, Davies JC. 2012. Basic science for the chest physician: Pseudomonas aeruginosa and the cystic fibrosis airway. Thorax 67: 465-467.

Williams B, Robinette M, Slovis B, Deretci V, Perkett E. 2008. Hydroxychloroquine-Pilot study of anti-inflammatory effects in cystic fibrosis. Pediatr Pulmonol 43 (Suppl 31): 314.

Zelvyte I, Dominaitiene R, Crisby M, Janciauskiene S. 2002. Modulation of inflammatory mediators and PPAR $\gamma$ and $\mathrm{NF \kappa B}$ expression by pravastatin in response to lipoproteins in human monocytes in vitro. Pharmacol Res 45: $147-154$.

Zhao J, Schloss PD, Kalikin LM, Carmody LA, Foster BK, Petrosino JF, Cavalcoli JD, VanDevanter DR, Murray S, Li JZ, et al. 2012. Decade-long bacterial community dynamics in cystic fibrosis airways. Proc Natl Acad Sci 109: 5809-5814.

Zingarelli B, Sheehan M, Hake PW, O'Connor M, Denenberg A, Cook JA. 2003. Peroxisome proliferator activator receptor- $\gamma$ ligands, 15 -deoxy- $\Delta^{12,14}$-prostaglandin $\mathrm{J}_{2}$ and ciglitazone, reduce systemic inflammation in polymicorbial sepsis by modulation of signal transduction pathways. J Immunol 171: 6827-6837. 


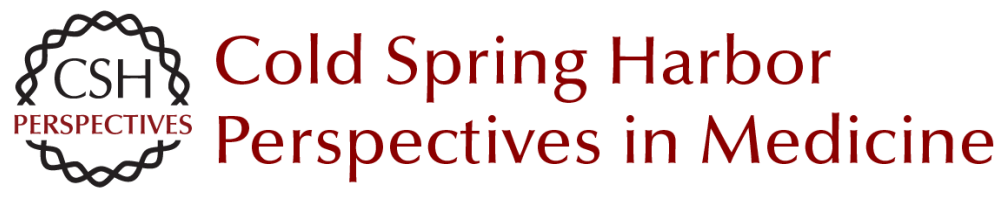

\section{Antibiotic and Anti-Inflammatory Therapies for Cystic Fibrosis}

James F. Chmiel, Michael W. Konstan and J. Stuart Elborn

Cold Spring Harb Perspect Med 2013; doi: 10.1101/cshperspect.a009779 originally published online July 23, 2013

\section{Subject Collection Cystic Fibrosis}

Antibiotic and Anti-Inflammatory Therapies for Cystic Fibrosis

James F. Chmiel, Michael W. Konstan and J. Stuart Elborn

Structure and Function of the Mucus Clearance System of the Lung

Brenda M. Button and Brian Button

New Pulmonary Therapies Directed at Targets

Other than CFTR

Scott $H$. Donaldson and Luis Galietta

The Cystic Fibrosis Airway Microbiome Susan V. Lynch and Kenneth D. Bruce

Cystic Fibrosis Transmembrane Conductance Regulator (ABCC7) Structure John F. Hunt, Chi Wang and Robert C. Ford

Status of Fluid and Electrolyte Absorption in Cystic Fibrosis

M.M. Reddy and M. Jackson Stutts

The Influence of Genetics on Cystic Fibrosis

Phenotypes

Michael R. Knowles and Mitchell Drumm

Perspectives on Mucus Properties and Formation

--Lessons from the Biochemical World

Daniel Ambort, Malin E.V. Johansson, Jenny K.

Gustafsson, et al.
The Cystic Fibrosis Intestine

Robert C. De Lisle and Drucy Borowitz

Cystic Fibrosis Transmembrane Regulator

Correctors and Potentiators

Steven M. Rowe and Alan S. Verkman

The Cystic Fibrosis of Exocrine Pancreas

Michael Wilschanski and Ivana Novak

Dynamics Intrinsic to Cystic Fibrosis

Transmembrane Conductance Regulator Function and Stability

P. Andrew Chong, Pradeep Kota, Nikolay V.

Dokholyan, et al.

The Cystic Fibrosis Gene: A Molecular Genetic

Perspective

Lap-Chee Tsui and Ruslan Dorfman

The CFTR Ion Channel: Gating, Regulation, and

Anion Permeation

Tzyh-Chang Hwang and Kevin L. Kirk

Assessing the Disease-Liability of Mutations in CFTR

Claude Ferec and Garry R. Cutting

Supramolecular Dynamics of Mucus

Pedro Verdugo

For additional articles in this collection, see http://perspectivesinmedicine.cshlp.org/cgi/collection/ 